\title{
Influence of cation substitution on electrical conductivity and optical absorption edge in $\mathrm{Cu}_{7}\left(\mathrm{Ge}_{1-\mathrm{x}} \mathrm{Si}_{\mathbf{x}}\right) \mathrm{S}_{5} \mathrm{I}$ mixed crystals
}

\author{
I.P. Studenyak ${ }^{1}$, M. Kranjěec ${ }^{2}$, V.V. Bilanchuk ${ }^{1}$, A. Dziaugys ${ }^{3}$, J. Banys ${ }^{3}$, A.F. Orliukas ${ }^{3}$ \\ ${ }^{1}$ Uzhhorod National University, Physics Faculty,46, Pidhirna str. 88000 Uzhhorod, Ukraine \\ ${ }^{2}$ University of Zagreb, Geotechnical Faculty, Hallerova Aleja 7, 42000 Varaždin, Croatia \\ ${ }^{3}$ Vilnius University, Physics Faculty, \\ Sauletekio al.9, LT-10222 Vilnius, Lithuania, e-mail: studenyak@dr.com
}

\begin{abstract}
Electrical conductivity of $\mathrm{Cu}_{7}\left(\mathrm{Ge}_{1-\mathrm{x}} \mathrm{Si}_{\mathrm{x}}\right) \mathrm{S}_{5} \mathrm{I}$ mixed crystals was measured in the frequency range $1.0 \cdot 10^{6}-1.2 \cdot 10^{9} \mathrm{~Hz}$ and in the temperature interval $100-300 \mathrm{~K}$. The frequency and temperature behaviour of the electrical conductivity were analyzed. The optical absorption edge of $\mathrm{Cu}_{7}\left(\mathrm{Ge}_{1-\mathrm{x}} \mathrm{Si}_{\mathrm{x}}\right) \mathrm{S}_{5} \mathrm{I}$ mixed crystals within the temperature range $77-300 \mathrm{~K}$ was studied. The compositional dependences of the electrical conductivity, activation energy, optical pseudogap and Urbach energy were obtained. The influence of $\mathrm{Ge} \rightarrow \mathrm{Si}$ cation substitution on the optical absorption processes in the $\mathrm{Cu}_{7}\left(\mathrm{Ge}_{1-\mathrm{x}} \mathrm{Si}_{\mathrm{x}}\right) \mathrm{S}_{5} \mathrm{I}$ mixed crystals is investigated.
\end{abstract}

Keywords: mixed crystals, electrical conductivity, activation energy, absorption edge, Urbach rule.

Manuscript received 25.06.12; revised version received 16.08.12; accepted for publication 10.09.12; published online 25.09.12.

\section{Introduction}

$\mathrm{Cu}_{7} \mathrm{GeS}_{5} \mathrm{I}$ and $\mathrm{Cu}_{7} \mathrm{SiS}_{5} \mathrm{I}$ superionic crystals belong to argyrodite family compounds [1]. Due to their high ionic conductivity, these crystals are attractive materials for applications in different functional elements of solid state ionics [2].

Structural, electrical and optical properties of $\mathrm{Cu}_{7} \mathrm{GeS}(\mathrm{Se})_{5} \mathrm{I}$ and mixed crystals based on them were studied in papers [3-7]. It is shown that the electrical conductivity of $\mathrm{Cu}_{7} \mathrm{GeSe}_{5} \mathrm{I}$ crystal at room temperature was found to be rather high $(64 \mathrm{~S} / \mathrm{m}$ at $295 \mathrm{~K}$ and $10^{6} \mathrm{~Hz}$ ) and typical for advanced superionic conductors $[5,6]$. At $\mathrm{S} \rightarrow \mathrm{Se}$ anionic substitution, the nonlinear increase of the electric conductivity by more than an order of magnitude was observed in $\mathrm{Cu}_{7} \mathrm{Ge}\left(\mathrm{S}_{1-\mathrm{x}} \mathrm{Se}_{\mathrm{x}}\right)_{5} \mathrm{I}$ mixed crystals [7]. Optical studies have shown that the absorption edge of $\mathrm{Cu}_{7} \mathrm{GeS}(\mathrm{Se}) \mathrm{S}_{5} \mathrm{I}$ crystals and mixed crystals based on them exhibits Urbach behaviour in a wide temperature range [3,5-7]. A nonlinear decrease of the optical pseudogap in the $\mathrm{Cu}_{7} \mathrm{Ge}\left(\mathrm{S}_{1-\mathrm{x}} \mathrm{Se}_{\mathrm{x}}\right)_{5} \mathrm{I}$ mixed crystals at $\mathrm{S} \rightarrow \mathrm{Se}$ anionic substitution is observed [7].
Some of the chemical and physics properties of $\mathrm{Cu}_{7} \mathrm{Ge}\left(\mathrm{S}_{1-\mathrm{x}} \mathrm{Se}_{\mathrm{x}}\right)_{5} \mathrm{I}$ mixed crystals were presented in the paper [8]. Chemical interaction in the $\mathrm{Cu}_{7} \mathrm{GeS}_{5} \mathrm{I}-$ $\mathrm{Cu}_{7} \mathrm{SiS}_{5} \mathrm{I}$ system was studied by X-ray phase analysis, microstructural analysis and density determination. The short-wave edge of the diffuse reflection spectra of $\mathrm{Cu}_{7}\left(\mathrm{Ge}_{1-\mathrm{x}} \mathrm{Si}_{\mathrm{x}}\right) \mathrm{S}_{5} \mathrm{I}$ mixed crystals is shown to shift towards shorter wavelengths after the substitution of $\mathrm{Ge}$ atoms by $\mathrm{Si}[8]$.

This paper is aimed at investigation of temperature and compositional behaviour of the electrical conductivity and optical absorption edge in $\mathrm{Cu}_{7}\left(\mathrm{Ge}_{1-\mathrm{x}} \mathrm{Si}_{\mathrm{x}}\right) \mathrm{S}_{5} \mathrm{I}$ mixed crystals. Moreover, the influence of different types of the crystal lattice disordering on absorption edge formation will be in focus of the paper.

\section{Experimental}

$\mathrm{Cu}_{7}\left(\mathrm{Ge}_{1-\mathrm{x}} \mathrm{Si}_{\mathrm{x}}\right) \mathrm{S}_{5} \mathrm{I}$ mixed crystals were grown by chemical vapour transport [8]. For synthesis, the calculated stoichiometric amounts of $\mathrm{Cu}, \mathrm{Si}, \mathrm{Ge}, \mathrm{S}$ and $\mathrm{CuI}$ were loaded in silica glass ampoules, thoroughly mixed, pumped out to $0.13 \mathrm{~Pa}$ and sealed. Additional amount of 
$\mathrm{CuI}$ used as a transport agent $\left(20 \mathrm{mg} / \mathrm{cm}^{3}\right.$ of the ampoule free volume) was also loaded in the ampoules. Thus, the crystal growth was carried out in atmosphere of $\mathrm{CuI}$ chemical active vapour. The as-grown crystals had the shape of plane-parallel platelets or distorted tetrahedra $5 \times 3 \times 3(2.5) \mathrm{mm}$ in size.

For X-ray studies, the DRON-3 diffractometer was used (conventional $\theta-2 \theta$ scanning technique, Bragg angle $2 \theta \cong 10-60^{\circ}, \mathrm{Cu} \mathrm{K} \mathrm{K}_{\alpha}, \mathrm{Ni}$ filtered radiation). It is shown that in the $\mathrm{Cu}_{7} \mathrm{GeS}_{5} \mathrm{I}-\mathrm{Cu}_{7} \mathrm{SiSeI}$ system a row of continuous solid solutions is formed with $F \overline{4} 3 m$ cubic symmetry at room temperature (Fig. 1).

The measurements of complex electrical conductivity were carried out within the frequency range $1.0 \cdot 10^{6}-1.2 \cdot 10^{9} \mathrm{~Hz}$ and the temperature interval 100 $300 \mathrm{~K}$ by using a coaxial impedance spectrometer setup [9].

Spectrometric studies of the optical absorption edge were carried out within the temperature range $77-300 \mathrm{~K}$ by using the LOMO KSVU-23 grating monochromator [10]. For these measurements, the samples were oriented at room temperature while being in the cubic phase. For low temperature studies cryostat of UTREX type was used. The relative error in determination of the relative change in the absorption coefficient $\Delta \alpha / \alpha$ did not exceed $10 \%$ at $0.3 \leq \alpha d \leq 3$ [11].

\section{Results and discussion}

It should be noted that measurements of the real bulk conductivity are limited to low frequencies (up to $\mathrm{MHz}$ range) due to contact effects. The frequency dependences of the real part of complex electrical conductivity $\sigma^{\prime}$ are illustrated for $\mathrm{Cu}_{7}\left(\mathrm{Ge}_{0.4} \mathrm{Si}_{0.6}\right) \mathrm{S}_{5} \mathrm{I}$ mixed crystal and at various temperatures are presented in Fig. 2. Influence of the contact effect is observed at low temperatures within the low-frequency range. With temperature increase, only relaxation dispersion of the electrical conductivity due to bulk conductivity takes place (Fig. 2). Besides, it is shown (Fig. 2) that with the temperature increase the $\sigma^{\prime}$ value for $\mathrm{Cu}_{7}\left(\mathrm{Ge}_{0.4} \mathrm{Si}_{0.6}\right) \mathrm{S}_{5} \mathrm{I}$ mixed crystal increases linearly in a semilogarithmic scale and obeys the Arrhenius law:

$\sigma^{\prime}=\frac{\sigma_{0}^{\prime}}{T} \exp \left(-\frac{\Delta E_{a}}{k T}\right)$,

where $\Delta E_{a}$ is the activation energy, $\sigma_{0}^{\prime}$ is some constant, $k$ is the Boltzmann constant, $T$ is the temperature.

Substitution of $\mathrm{Ge}$ atoms with $\mathrm{Si}$ atoms leads to decreasing the electrical conductivity $\sigma^{\prime}$ (Fig. 3). It should be noted that in comparison with $\mathrm{Cu}_{7} \mathrm{GeS}_{5} \mathrm{I}$, in $\mathrm{Cu}_{7} \mathrm{SiSe}_{5} \mathrm{I}$ crystals the $\sigma^{\prime}$ value decreases by more than an order of magnitude. With the increase of Si content, the $\sigma^{\prime}$ value of $\mathrm{Cu}_{7} \mathrm{Ge}\left(\mathrm{S}_{1-\mathrm{x}} \mathrm{Se}_{\mathrm{x}}\right)_{5} \mathrm{I}$ mixed crystals decreases nonlinearly with downward bowing, besides reaches a minimum at $x=0.4$. The activation energy
$\Delta E_{a}$ in the mixed crystals under investigation increases within the composition interval $0<x \leq 0.4$ achieves its maximum at $x=0.4$ and decreases within the composition interval $0.4<x<1$ (Fig. 3).

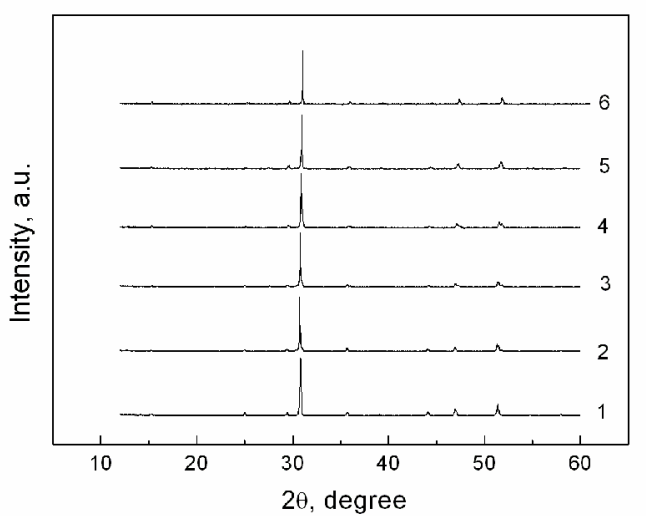

Fig. 1. X-ray diffraction patterns for $\mathrm{Cu}_{7}\left(\mathrm{Ge}_{1-\mathrm{x}} \mathrm{Si}_{\mathrm{x}}\right) \mathrm{S}_{5} \mathrm{I}$ mixed crystals: $\quad 1-\mathrm{Cu}_{7} \mathrm{GeS}_{5} \mathrm{I}, \quad 2-\mathrm{Cu}_{7}\left(\mathrm{Ge}_{0.8} \mathrm{Si}_{0.2}\right) \mathrm{S}_{5} \mathrm{I}, \quad 3-$ $\mathrm{Cu}_{7}\left(\mathrm{Ge}_{0.6} \mathrm{Si}_{0.4}\right) \mathrm{S}_{5} \mathrm{I}, 4-\mathrm{Cu}_{7}\left(\mathrm{Ge}_{0.4} \mathrm{Si}_{0.6}\right) \mathrm{S}_{5} \mathrm{I}, 5-\mathrm{Cu}_{7}\left(\mathrm{Ge}_{0.8} \mathrm{Si}_{0.2}\right) \mathrm{S}_{5} \mathrm{I}$, $6-\mathrm{Cu}_{7} \mathrm{SiS}_{5} \mathrm{I}$.

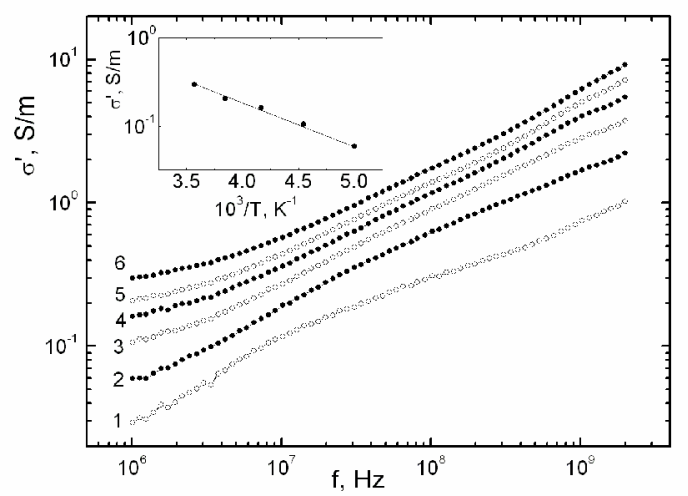

Fig. 2. Frequency dependences of the real part of complex electrical conductivity $\sigma^{\prime}$ for $\mathrm{Cu}_{7}\left(\mathrm{Ge}_{0.4} \mathrm{Si}_{0.6}\right) \mathrm{S}_{5} \mathrm{I}$ mixed crystal measured at various temperatures $T(\mathrm{~K}): 1-180,2-200,3-$ $220,4-240,5-260,6-280$. The insert shows the temperature dependence of electrical conductivity $\sigma^{\prime}$ for $\mathrm{Cu}_{7}\left(\mathrm{Ge}_{0.4} \mathrm{Si}_{0.6}\right) \mathrm{S}_{5} \mathrm{I}$ mixed crystal.

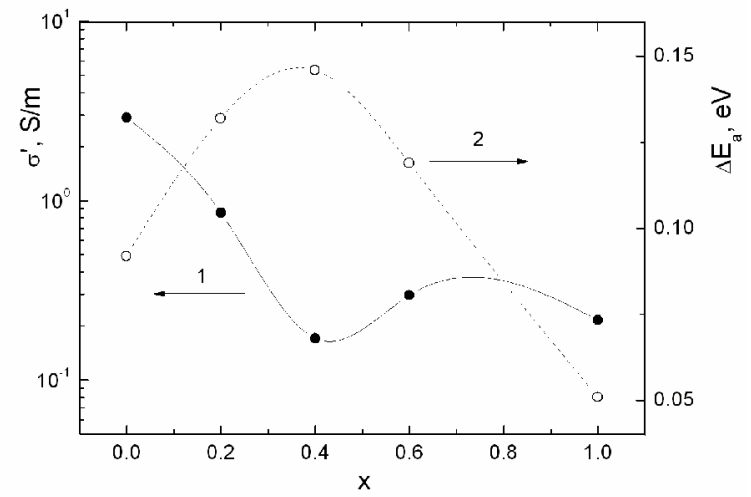

Fig. 3. Compositional dependences of the real part of complex electrical conductivity $\sigma^{\prime}(1)$ and activation energy $\Delta E_{a}(2)$ for $\mathrm{Cu}_{7}\left(\mathrm{Ge}_{1-\mathrm{x}} \mathrm{Si}_{\mathrm{x}}\right) \mathrm{S}_{5} \mathrm{I}$ mixed crystals. 
Temperature studies of the optical absorption spectra have shown that in the temperature interval 77 $300 \mathrm{~K}$, within the range of direct allowed interband transitions, the absorption edge in $\mathrm{Cu}_{7}\left(\mathrm{Ge}_{1-\mathrm{x}} \mathrm{Si}_{\mathrm{x}}\right) \mathrm{S}_{5} \mathrm{I}$ mixed crystals has an exponential shape, which is described by the Urbach rule [12]

$\alpha(h v, T)=\alpha_{0} \cdot \exp \left[\frac{h v-E_{0}}{E_{\mathrm{U}}(T)}\right]$,

where $E_{U}$ is the Urbach energy (a reciprocal of the absorption edge slope $\left.E_{\mathrm{U}}^{-1}=\Delta(\ln \alpha) / \Delta(h v)\right)$, $\sigma=k T / E_{\mathrm{U}}$ is the absorption edge steepness parameter, $\alpha_{0}$ and $E_{0}$ are the convergence point coordinates of the Urbach bundle, $h v$ is the photon energy. Temperature behaviour of the Urbach absorption edge for $\mathrm{Cu}_{7}\left(\mathrm{Ge}_{0.4} \mathrm{Si}_{0.6}\right) \mathrm{S}_{5} \mathrm{I}$ crystal, which is typical for the mixed crystals under investigation, is shown in Fig. 4. The constants $\alpha_{0}$ and $E_{0}$ for $\mathrm{Cu}_{7}\left(\mathrm{Ge}_{1-\mathrm{x}} \mathrm{Si}_{\mathrm{x}}\right) \mathrm{S}_{5} \mathrm{I}$ mixed crystals are given in Table.

Our analysis of the absorption edge has shown that the temperature dependence of the absorption edge steepness parameter $\sigma(T)$ for $\mathrm{Cu}_{7}\left(\mathrm{Ge}_{1-\mathrm{x}} \mathrm{Si}_{\mathrm{x}}\right) \mathrm{S}_{5} \mathrm{I}$ mixed crystals is well described by the Mahr formula

$\sigma(T)=\sigma_{0} \cdot\left(\frac{2 k T}{\hbar \omega_{p}}\right) \cdot \tanh \left(\frac{\hbar \omega_{p}}{2 k T}\right)$,

where $\hbar \omega_{p}$ is the effective phonon energy in the oneoscillator model, describing the electron-phonon interaction (EPI), and $\sigma_{0}$ is a parameter related to the EPI constant $g$ as $\sigma_{0}=(2 / 3) g^{-1}$ [13]. The obtained using Eq. (3) values of the effective phonon energy $\hbar \omega_{p}$ and the EPI parameter $\sigma_{0}$ for $\mathrm{Cu}_{7}\left(\mathrm{Ge}_{1-\mathrm{x}} \mathrm{Si}_{\mathrm{x}}\right) \mathrm{S}_{5} \mathrm{I}$ mixed crystals are listed in Table. For pure $\mathrm{Cu}_{7} \mathrm{Ge}(\mathrm{Si}) \mathrm{S}_{5} \mathrm{I}$ crystals as well as for $\mathrm{Cu}_{7}\left(\mathrm{Ge}_{1-\mathrm{x}} \mathrm{Si}_{\mathrm{x}}\right) \mathrm{S}_{5} \mathrm{I}$ mixed crystals, the value $\sigma_{0}<1$ that indicates a strong EPI. It should be noted that EPI in mixed crystals is enhanced (Table).

Temperature dependences of the optical pseudogap $E_{g}^{*}\left(E_{g}^{*}\right.$ is the absorption edge energy position at a fixed value of the absorption coefficient $\left.\alpha=10^{3} \mathrm{~cm}^{-1}[10]\right)$ and Urbach energy $E_{\mathrm{U}}$ for $\mathrm{Cu}_{7}\left(\mathrm{Ge}_{0.4} \mathrm{Si}_{0.6}\right) \mathrm{S}_{5} \mathrm{I}$ crystal are depicted in Fig. 5. It is shown that $E_{g}^{*}$ value decreases nonlinearly with temperature, and $E_{\mathrm{U}}$ value increases nonlinearly without any singularities (Fig. 5). Besides, the temperature dependences of $E_{g}^{*}$ and $E_{\mathrm{U}}$ for $\mathrm{Cu}_{7}\left(\mathrm{Ge}_{1-\mathrm{x}} \mathrm{Si}_{\mathrm{x}}\right) \mathrm{S}_{5} \mathrm{I}$ mixed crystals are well described in the framework of the Einstein model by the relationships $[14,15]$

$E_{g}^{*}(T)=E_{g}^{*}(0)-S_{g}^{*} k \theta_{\mathrm{E}}\left[\frac{1}{\exp \left(\theta_{\mathrm{E}} / T\right)-1}\right]$,

$E_{\mathrm{U}}=\left(E_{\mathrm{U}}\right)_{0}+\left(E_{\mathrm{U}}\right)_{1}\left[\frac{1}{\exp \left(\theta_{\mathrm{E}} / T\right)-1}\right]$,

where $S_{g}^{*}$ is a dimensionless constant of interaction, $\theta_{\mathrm{E}}$ is the Einstein temperature, corresponding to the average frequency of phonon excitations of a system of noninteracting oscillators, $\left(E_{\mathrm{U}}\right)_{0}$ and $\left(E_{\mathrm{U}}\right)_{1}$ are constant values. The adjustment parameters $E_{g}^{*}(0), S_{g}^{*}, \theta_{\mathrm{E}}$, $\left(E_{\mathrm{U}}\right)_{0}$ and $\left(E_{\mathrm{U}}\right)_{1}$ are listed in Table.

The compositional studies show that the increase of content for $\mathrm{Si}$ atoms in the $\mathrm{Cu}_{7}\left(\mathrm{Ge}_{1-\mathrm{x}} \mathrm{Si}_{\mathrm{x}}\right) \mathrm{S}_{5} \mathrm{I}$ mixed crystals leads to a nonlinear increase with downward bowing of the optical pseudogap $E_{g}^{*}$ (Fig. 6). At $\mathrm{Ge} \rightarrow \mathrm{Si}$ cationic substitution, the Urbach energy $E_{\mathrm{U}}$ in the

Table. Urbach edge parameters and EPI parameters of $\mathrm{Cu}_{7}\left(\mathrm{Ge}_{1-\mathrm{x}} \mathrm{Si}_{\mathrm{x}}\right) \mathrm{S}_{5} \mathrm{I}$ mixed crystals.

\begin{tabular}{|l|c|c|c|c|c|c|}
\hline Crystal & $x=0$ & $x=0.2$ & $x=0.4$ & $x=0.6$ & $x=0.8$ & $x=1$ \\
\hline$\alpha_{0}\left(\mathrm{~cm}^{-1}\right)$ & $1.1 \cdot 10^{6}$ & $2.6 \cdot 10^{4}$ & $8.3 \cdot 10^{4}$ & $6.2 \cdot 10^{4}$ & $8.3 \cdot 10^{4}$ & $7.8 \cdot 10^{5}$ \\
\hline$E_{0}(\mathrm{eV})$ & 2.371 & 2.801 & 3.146 & 3.128 & 3.034 & 2.593 \\
\hline$E_{g}^{*}(300 \mathrm{~K})(\mathrm{eV})$ & 2.125 & 2.136 & 2.148 & 2.171 & 2.207 & 2.250 \\
\hline$E_{\mathrm{U}}(300 \mathrm{~K})(\mathrm{meV})$ & 35 & 206 & 228.6 & 235 & 190 & 52 \\
\hline$\sigma_{0}$ & 0.81 & 0.199 & 0.187 & 0.185 & 0.213 & 0.60 \\
\hline$\hbar \omega_{p}(\mathrm{meV})$ & 28.7 & 73.7 & 77.2 & 78.6 & 71.0 & 43.1 \\
\hline$\theta_{\mathrm{E}}(\mathrm{K})$ & 333 & 855 & 896 & 912 & 824 & 511 \\
\hline$\left(E_{\mathrm{U}}\right)_{0}(\mathrm{meV})$ & 17.8 & 185.4 & 206.9 & 213.3 & 167.1 & 35.9 \\
\hline$\left(E_{\mathrm{U}}\right)_{1}(\mathrm{meV})$ & 35.1 & 365.8 & 403.5 & 425.6 & 327.2 & 75.1 \\
\hline$E_{g}^{*}(0)(\mathrm{eV})$ & 2.247 & 2.200 & 2.228 & 2.251 & 2.271 & 2.365 \\
\hline$S_{g}^{*}$ & 8.5 & 14.2 & 19.8 & 20.4 & 13.2 & 12.3 \\
\hline
\end{tabular}


composition interval $0 \leq x \leq 0.2$ drastically increases (by a factor higher than 5) and at $x=0.6$ it reaches the maximum value, then in the composition interval $0.8 \leq x \leq 1$ decreases with $x$ by a factor higher than 3 . The significant increase of the Urbach energy $E_{\mathrm{U}}$ in $\mathrm{Cu}_{7}\left(\mathrm{Ge}_{1-\mathrm{x}} \mathrm{Si}_{\mathrm{x}}\right) \mathrm{S}_{5} \mathrm{I}$ mixed crystals is caused by the substantial compositional disordering of their crystal lattice.

It should be noted that the Urbach energy $E_{U}$ characterizes the degree of the edge smearing due to the different types of disordering of the crystal lattice. In $\mathrm{Cu}_{7}\left(\mathrm{Ge}_{1-\mathrm{x}} \mathrm{Si}_{\mathrm{x}}\right) \mathrm{S}_{5} \mathrm{I}$ mixed crystals, besides the temperature-related (due to the lattice thermal vibrations) and structural (static and dynamical) disordering characteristic for pure $\mathrm{Cu}_{7} \mathrm{Ge}(\mathrm{Si}) \mathrm{S}_{5} \mathrm{I}$ crystals, compositional disordering should also be revealed. In [16], it was shown that the temperature-related, structural, and compositional disordering affect the Urbach absorption edge shape, i.e. the Urbach energy $E_{\mathrm{U}}$ is described by the following equation

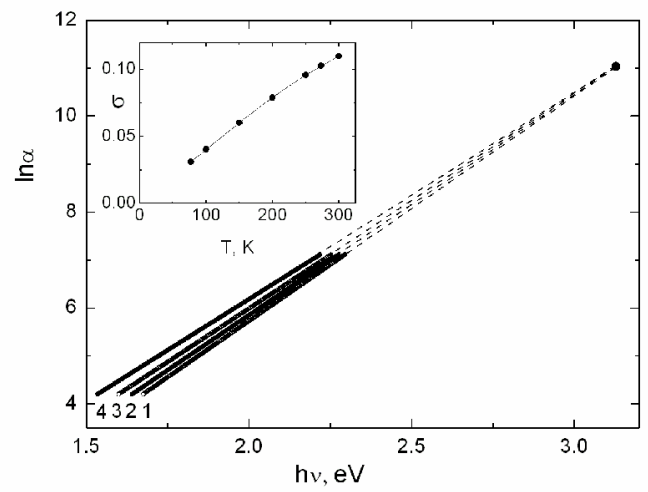

Fig. 4. Spectral dependences of the Urbach absorption edge for $\mathrm{Cu}_{7}\left(\mathrm{Ge}_{0.4} \mathrm{Si}_{0.6}\right) \mathrm{S}_{5} \mathrm{I}$ mixed crystal at various temperatures $T(\mathrm{~K})$ : $1-77,2-200,3-250,4-300$. The insert shows the temperature dependence of $\sigma$ steepness parameter.

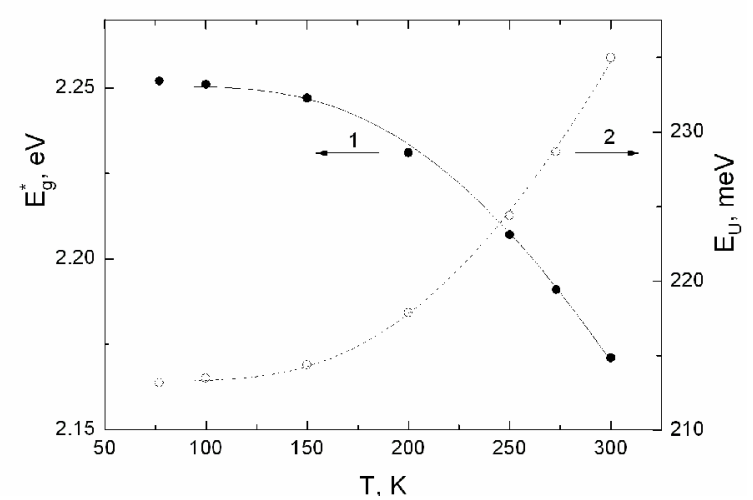

Fig. 5. Temperature dependences of the optical pseudogap $E_{g}^{*}(1)$ and Urbach energy $E_{\mathrm{U}}(2)$ for the $\mathrm{Cu}_{7}\left(\mathrm{Ge}_{0.4} \mathrm{Si}_{0.6}\right) \mathrm{S}_{5} \mathrm{I}$ mixed crystal: circles - experiment, curves - calculations.
$E_{\mathrm{U}}=\left(E_{\mathrm{U}}\right)_{T}+\left(E_{\mathrm{U}}\right)_{X}+\left(E_{\mathrm{U}}\right)_{C}$,

where $\left(E_{U}\right)_{T},\left(E_{U}\right)_{X}$, and $\left(E_{U}\right)_{C}$ are contributions of temperature-related and structural disordering to $E_{\mathrm{U}}$, respectively. The first term in the right-hand side of Eq. (5) represents the static structural disordering for pure crystals or sum of static structural disordering and compositional disordering for mixed crystals, and the second one - the temperature-related types of disordering: temperature disordering due to thermal lattice vibrations and dynamic structural disordering due to presence of mobile ions in superionic conductors. The calculations have shown that the contribution of static structural disordering into the Urbach energy $E_{\mathrm{U}}$ at $T=$ $300 \mathrm{~K}$ for $\mathrm{Cu}_{7} \mathrm{GeS}_{5} \mathrm{I}$ crystals is $51 \%$, while for $\mathrm{Cu}_{7} \mathrm{SiSe}_{5} \mathrm{I}$ it is $69 \%$. Within the framework of the procedure, described in [17], the relative contributions of different type disordering into the Urbach energy were estimated and adduced in Fig. 7. It is shown for $\mathrm{Cu}_{7} \mathrm{Ge}\left(\mathrm{S}_{1-\mathrm{x}} \mathrm{Se}_{\mathrm{x}}\right)_{5} \mathrm{I}$ mixed crystals that $\mathrm{Ge} \rightarrow \mathrm{Si}$ cation

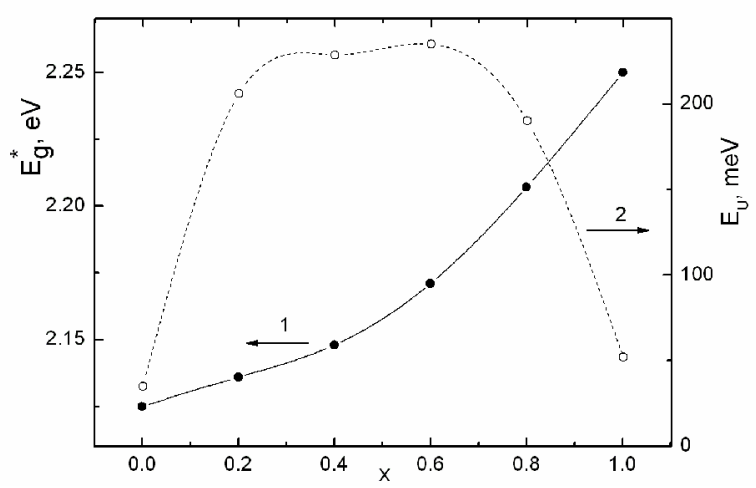

Fig. 6. Compositional dependences of the optical pseudogap $E_{g}^{*}(1)$ and Urbach energy $E_{U}(2)$ for the $\mathrm{Cu}_{7}\left(\mathrm{Ge}_{1-\mathrm{x}} \mathrm{Si}_{\mathrm{x}}\right) \mathrm{S}_{5} \mathrm{I}$ mixed crystals.

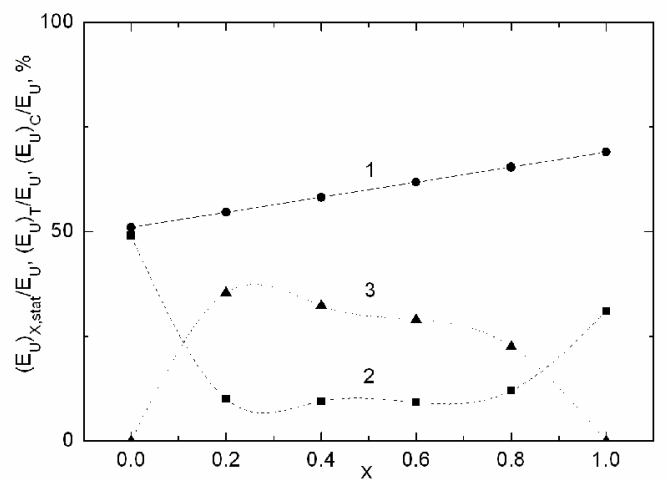

Fig. 7. Relative contributions of static structural disordering $\left(E_{U}\right)_{X, \text { stat }} / E_{U}(1), \quad$ temperature-related disordering $\left(E_{U}\right)_{T} / E_{U}$ (2) and compositional disordering $\left(E_{U}\right)_{C} / E_{U}$ (3) into $E_{\mathrm{U}}$ at $T=300 \mathrm{~K}$ for $\mathrm{Cu}_{7}\left(\mathrm{Ge}_{1-\mathrm{x}} \mathrm{Si}_{\mathrm{x}}\right) \mathrm{S}_{5} \mathrm{I}$ mixed crystals. 
substitution results in a linear decrease of the relative contribution of the static structural disordering $\left(E_{U}\right)_{X, \text { stat }} / E_{U}$, a nonlinear decrease with a downward bowing of the temperature-related disordering $\left(E_{U}\right)_{T} / E_{U}$, and a nonlinear increase with an upward bowing of the compositional disordering $\left(E_{U}\right)_{C} / E_{U}$ into $E_{\mathrm{U}}$ at $300 \mathrm{~K}$.

\section{Conclusions}

The linear increase of electrical conductivity with temperature, which obeys the Arrhenius law, is observed in $\mathrm{Cu}_{7}\left(\mathrm{Ge}_{1-\mathrm{x}} \mathrm{Si}_{\mathrm{x}}\right) \mathrm{S}_{5} \mathrm{I}$ mixed crystals. The $\mathrm{Ge} \rightarrow \mathrm{Si}$ cationic substitution results in a nonlinear decrease of the electrical conductivity by more than an order of magnitude. It is noted that $\mathrm{Cu}_{7}\left(\mathrm{Ge}_{1-\mathrm{x}} \mathrm{Si}_{\mathrm{x}}\right) \mathrm{S}_{5} \mathrm{I}$ mixed crystals are characterized by rather high electric conductivity and low activation energy what puts them in line with the most efficient solid electrolytes.

It is shown that the Urbach absorption edge is observed in $\mathrm{Cu}_{7}\left(\mathrm{Ge}_{1-\mathrm{x}} \mathrm{Si}_{\mathrm{x}}\right) \mathrm{S}_{5} \mathrm{I}$ mixed crystals within the temperature interval $77-300 \mathrm{~K}$. Urbach behaviour of the absorption edge is related to the electron-phonon interaction that is strong for $\mathrm{Cu}_{7}\left(\mathrm{Ge}_{1-\mathrm{x}} \mathrm{Si}_{\mathrm{x}}\right) \mathrm{S}_{5} \mathrm{I}$ mixed crystals. It should be noted that the temperature dependences of optical pseudogap and Urbach energy for $\mathrm{Cu}_{7}\left(\mathrm{Ge}_{1-\mathrm{x}} \mathrm{Si}_{\mathrm{x}}\right) \mathrm{S}_{5} \mathrm{I}$ mixed crystals are well described in the framework of the Einstein model.

A nonlinear increase of the optical pseudogap in $\mathrm{Cu}_{7}\left(\mathrm{Ge}_{1-\mathrm{x}} \mathrm{Si}_{\mathrm{x}}\right) \mathrm{S}_{5} \mathrm{I}$ mixed crystals at $\mathrm{Ge} \rightarrow \mathrm{Si}$ cationic substitution is revealed while the compositional dependence of the Urbach energy exhibits typical behaviour for mixed crystals. The Urbach energy in $\mathrm{Cu}_{7}\left(\mathrm{Ge}_{1-\mathrm{x}} \mathrm{Si}_{\mathrm{x}}\right) \mathrm{S}_{5} \mathrm{I}$ mixed crystals is shown to be determined by the effect of the temperature-related, structural and compositional disordering.

\section{References}

1. W.F. Kuhs, R. Nitsche, K. Scheunemann, The argyrodites - a new family of the tetrahedrally close-packed srtuctures // Mater. Res. Bull. 14, p. 24-248 (1979).

2. A. Dziaugys, J. Banys, A. Kezionis, V. Samulionis, I. Studenyak, Conductivity investigations of $\mathrm{Cu}_{7} \mathrm{GeS}_{5} \mathrm{I}$ family fast-ion conductors // Solid State Ionics, 179, p. 168-171 (2008).

3. I.P. Studenyak, M. Kranjčec, Gy.Sh. Kovacs, I.D. Desnica-Frankovic, A.A. Molnar, V.V. Panko, V.Yu. Slivka, Electrical and optical absoprtion studies of $\mathrm{Cu}_{7} \mathrm{GeS}_{5} \mathrm{I}$ fast-ion conductor // J. Phys. Chem. Solids, 63, p. 267-271 (2002).

4. I.P. Studenyak, O.P. Kokhan, M. Kranjčec, V.V. Bilanchuk, V.V. Panko, Influence of $\mathrm{S} \rightarrow \mathrm{Se}$ substitution on chemical and physical properties of $\mathrm{Cu}_{7}\left(\mathrm{Ge}_{1-\mathrm{x}} \mathrm{Si}_{\mathrm{x}}\right) \mathrm{S}_{5} \mathrm{I}$ superionic solid solutions // $\mathrm{J}$. Phys. Chem. Solids, 68, p. 1881-1884 (2007).
5. I.P. Studenyak, V.V. Bilanchuk, O.P. Kokhan, Yu.M. Stasyuk, A.F. Orliukas, A. Kezionis, E. Kazakevicius, T. Salkus, Electrical conductivity, electrochemical and optical properties of $\mathrm{Cu}_{7} \mathrm{GeS}_{5} \mathrm{I}-\mathrm{Cu}_{7} \mathrm{GeSe}_{5} \mathrm{I}$ superionic solid solutions // Lit. J. Phys. 49, p. 203-208 (2009).

6. I.P. Studenyak, M. Kranjčec, V.V. Bilanchuk, O.P. Kokhan, A.F. Orliukas, E. Kazakevicius, A. Kezionis, T. Salkus, Temperature variation of electrical conductivity and absorption edge in $\mathrm{Cu}_{7} \mathrm{GeSe}_{5} \mathrm{I}$ advanced superionic conductor // J. Phys. Chem. Solids, 70, p. 1478-1481 (2009).

7. I.P. Studenyak, M. Kranjčec, V.V. Bilanchuk, O.P. Kokhan, A.F. Orliukas, A. Kezionis, E. Kazakevicius, T. Salkus, Temperature and compositional behaviour of electrical conductivity and optical absorption edge in $\mathrm{Cu}_{7}\left(\mathrm{Ge}_{1-\mathrm{x}} \mathrm{Si}_{\mathrm{x}}\right) \mathrm{S}_{5} \mathrm{I}$ mixed superionic crystals // Solid State Ionics, 181, p. 1596-1600 (2010).

8 I.P. Studenyak, O.P. Kokhan, M. Kranjčec, M.I. Hrechyn, V.V. Panko, Crystal growth and phase interaction studies in $\mathrm{Cu}_{7} \mathrm{GeS}_{5} \mathrm{I}-\mathrm{Cu}_{7} \mathrm{SiS}_{5} \mathrm{I}$ superionic system // J. Cryst. Growth, 306, p. 326-329 (2007).

9. A.F. Orliukas, A. Kežionis, and E. Kazakevičius, Impedance spectroscopy of solid electrolytes in the radio frequency range // Solid State Ionics, 176, p. 2037-2043 (2005).

10. I.P. Studenyak, M. Kranjčec, Gy.Sh. Kovacs, V.V. Panko, D.I. Desnica, A.G. Slivka, P.P. Guranich, The effect of temperature and pressure on the optical absorption edge in $\mathrm{Cu}_{6} \mathrm{PS}_{5} \mathrm{X}(\mathrm{X}=\mathrm{Cl}, \mathrm{Br}, \mathrm{I})$ crystals // J. Phys. Chem. Solids, 60, p. 1897-1904 (1999).

11. F. Oswald, Zur meßgenauigkeit bei der bestimmung der absorptionskonstanten von halbleitern im infraroten spektralbereich // Optik, 16, p. 527-537 (1959).

12. F. Urbach, The long-wavelength edge of photographic sensitivity and electronic absorption of solids // Phys. Rev. 92, p. 1324-1326 (1953).

13. M.V. Kurik, Urbach rule (Review) // Phys. Status Solidi (a), 8, p. 9-30 (1971).

14. M. Beaudoin, A.J.G. DeVries, S.R. Johnson, H. Laman, T. Tiedje, Optical absorption edge of semi-insulating $\mathrm{GaAs}$ and $\mathrm{InP}$ at high temperatures // Appl. Phys. Lett. 70, p. 3540-3542 (1997).

15. Z. Yang, K.P. Homewood, M.S. Finney, M.A. Harry, K.J. Reeson, Optical absorption study of ion beam synthesized polycrystalline semiconducting $\mathrm{FeSi}_{2} / / \mathrm{J}$. Appl. Phys. 78, p. 1958-1963 (1995).

16. G.D. Cody, T. Tiedje, B. Abeles, B. Brooks, Y. Goldstein, Disorder and the optical-absorption edge of hydrogenated amorphous silicon // Phys. Rev. Lett. 47, p. 1480-1483 (1981).

17. I.P. Studenyak, M. Kranjčec, M.V. Kurik, Urbach rule and disordering processes in $\mathrm{Cu}_{6} \mathrm{P}\left(\mathrm{S}_{1-\mathrm{x}} \mathrm{Se}_{\mathrm{x}}\right)_{5} \mathrm{Br}_{1-\mathrm{y}} \mathrm{I}_{\mathrm{y}}$ superionic conductors // J. Phys. Chem. Solids, 67, p. 807-817 (2006). 